\title{
PERABIAKAN ALGORITMA SUHU PERMUKAAN LAUT LANDSAT 8 UNTUK PERAIRAN PONELO
}

\author{
Romansah Wumu ${ }^{1}$, Iqrimha staddal ${ }^{1}$, Evi Sunarti Antu ${ }^{1}$, Burhan Liputo ${ }^{1}$, Farid Darise ${ }^{1}$ \\ ${ }^{1}$ Tim Pengajar Pada Program Studi Mesin Dan Peralatan Pertanian, Politeknik \\ Gorontalo
}

\begin{abstract}
ABSTRAK
Suhu permukaan laut (SPL) merupakan salah satu parameter yang mempengaruhi kehidupan biota laut. Landsat menyediakan data suhu permukaan bumi sejak tahun 1978. Penelitian ini memfokuskan pada pebraikan algoritma Brightness Temperature (BT) pada band 10 dan 11 data Landsat 8 (L8) menjadi Suhu Permukaan Laut (SPL) untuk perairan Ponelo dengan metode regresi. Regresi yang diperoleh diuji menggunakan metode $\quad R$-squared $\left(\mathrm{R}^{2}\right)$ dan Root Mean Square Error (RMSE). Berdasarkan hasil pengambilan data dan analisis data L8 pada tanggal 21 Mei 2017 diperoleh algoritma polinomial 2 merupakan algoritma terbaik dengan dengan koefisien $\mathrm{a}_{0}, \mathrm{a}_{1}$, dan $\mathrm{a}_{2}$ secara berturut turut $3568.14,329.64$, dan $-7.55\left(\mathrm{R}^{2}=0.86\right.$ dan $\left.\mathrm{RMSE}=0.73\right)$.
\end{abstract}

Kata kunci : Algoritma, Regresi, Root Mean Square Error, R-squared

\begin{abstract}
Sea Surface Temperature (SST) is one of the parameters that affecting marine life. Landsat provides surface temperature data since 1978. This research focuses on improving the algorithm of a Brightness Temperature (BT) on band 10 and 11 data Landsat 8 (L8) to Sea Surface Temperature (SST). Data collection was done in Panelo waters using regression method. The regression obtained was tested using $R$-squared $\left(R^{2}\right)$ and Root Mean Square Error (RMSE) methods. Based on the results of data collection and analysis of L8 data on 21 May 2017 obtained that algorithm polynomial 2 is the best algorithm with coefficients $a 0$, al, and a2 respectively $3568.14,329.64$ and $-7.55 \quad\left(R^{2}=0.86\right.$ and $R M S E=0.73$ ).
\end{abstract}

Keywords: Algorithm, Regression, Root Mean Square Error, R-squared, Panelo Water 


\section{PENDAHULUAN}

\subsection{Latar belakang}

Indonesia merupakan Negara maritim dengan lautan $64,97 \%$ dari total luas Indonesia. Potensi terbesar terdapat pada potensi sumber daya laut. Keaneka ragaman dan jumlah ikan merupakan salah satu potensi laut Indonesia. Ekplorasi sumberdaya ikan masih belum maksimal, hal ini dikarenakan sebagian nelayan masih menggunakan cara tradisional berupa insting dan informasi dari sesama nelayan dalam menentukan Zona Potensi Penangkapan Ikan (ZPPI). Selain penentuan ZPPI yang masih secara tradisional, penentuan lokasi budidaya ikan laut (tambak) dan budidaya rumput laut tidak terencana dengan baik.

Suhu merupakan salah satu faktor yang mempengaruhi perkembangan dan pertumbuhan mahluk hidup. Perubahan suhu juga menjadi faktor yang mempengaruhi migrasi hewan. Pada kehidupan laut, suhu mempengaruhi siklus biogeokimia dan kualitas habitat perairan (Ding \& Elmore, 2015). Hal ini menyebabkan data rekaman suhu permukaan menjadi penting dalam perencanaan kesesuaian lahan budidaya di darat maupun laut. Penelitian ini membatasi pada Suhu Permukaan Laut (SPL) mengingat potensi laut Indonesia yang besar. SPL merupakan parameter penting dalam penentuan lokasi upwelling yang menjadi titik konsentrasi berkumpulnya ikan sehingga dapat dijadikan ZPPI (Hamzah, Prayogo, \& Harsanugraha, 2014; Hamzah, Prayogo, \& Marpaung, 2016). SPL juga dapat dijadikan parameter penentuan lokasi budidaya ikan laut dan rumput laut (Kartikasari, Jaelani, \& Winarso, 2016; Selamat, Samawi, Zainuddin, \& Massinai, 2015).

Citra satelit landsat telah merekam suhu permukaan bumi sejak tahun 1978 sampai saat ini. Saat ini landsat telah berada pada generasi ke-8 dengan nama Landsat-8 (L8). Perbedaan dengan generasi sebelumnya L8 dilengkapi dengan 2 kanal Thermal Infrared Sensor (TIRS) pada kisaran panjang gelombang 10 dan $12 \mu \mathrm{m}$ (Jiménez-
Muñoz et al. 2014). Hal ini membuka kemungkinan untuk pengembangan algoritma SPL.

\subsection{Rumusan Masalah}

Bagaimanakah hasil perbaikan algoritma SPL untuk data Landsat 8 (L8) pada perairan Ponelo?

\subsection{Tujuan}

Memperbaiki algoritma SPL data L8 untuk perairan Ponelo

\subsection{Manfaat Penelitian}

Menghasilkan algoritma SPL yang bermanfaat untuk perencanaan ekspolorasi sumberdaya laut.

\section{TINJAUAN PUSTAKA}

\subsection{Landsat 8}

Landsat 8 diluncurkan pada tanggal 11 Februari 2013, menggantikan dan menyempurnakan fungsi dari landsat 7 yang menggalami kerusakan sejak Mei 2003 pada Scan Line Corrector-nya, sehingga kehilangan data sebesar 24 persen sepanjang sisi-sisi luar dari masing-masing citra (USGS 2013b, 2013a).

Landsat 8 dilengkapi dengan Data Thermal Infrared Sensor (TIRS) terdapat pada Band 10 dan 11. Data L8 level 1T merupakan data dalam bentuk Digintal Number (DN) untuk memperoleh Brightness Temperature (BT) harus dilakukan koreksi radiometric menggunakan metode gain offset untuk memperoleh data Spectral Radiance (L $\lambda$ ) (Sahana, Ahmed, and Sajjad 2016; Syariz et al. 2015; Kartikasari, Jaelani, and Winarso 2016).

$$
L_{\lambda}=M_{\lambda} \times Q_{\text {Cal }}+A_{\lambda}
$$

$\mathrm{L} \lambda$ merupakan radian sensor (ToA) $(\mathrm{W} /(\mathrm{m} 2 . \mathrm{sr} . \mu \mathrm{m})), \quad \mathrm{M} \lambda \quad$ adalah radiance_mult_band_n, QCal adalah nilai $\mathrm{DN}$, dan $\mathrm{A} \lambda$ adalah radiance add_band_n, dimana $\mathrm{n}$ adalah nomor kanal. Data $\mathrm{M} \lambda \mathrm{A} \lambda$ terdapat pada meta data L8. Data $\mathrm{L} \lambda$ kemudian dikonfersi menjadi data BT dengan menggunakan persamaan berikut. 


$$
T=\frac{K_{2}}{\ln \left(\frac{K_{1}}{L_{\lambda}}+1\right)} \ldots
$$

$\mathrm{T}$ merupakan BT (Kelvin), K1 dan K2 merupakan konstanta konversi (dapat dilihat pada meta data L8) (Sahana, Ahmed, and Sajjad 2016; Syariz et al. 2015; Kartikasari, Jaelani, and Winarso 2016)..

\subsection{Algoritma Suhu Permukaan Laut}

Suhu Pemukaan Laut (SPL) atau Sea Surface Temperature (SST) umumnya sering digunakan dalam bidang kelautan maupun perikanan yang merupakan bagian dari suhu perairan secara keseluruhan. SPL dipengaruhi oleh panas matahari, arus permukaan, keadaan awan, upwelling, divergensi, dan konvergensi terutama pada daerah muara dan sepanjang garis pantai (Arief et al. 2015).

Data BT dari hasil pengolahan data L8 dapat dapat dikonfersi menjadi SPL menggunakan pendekatan korelasi antara SPL insitu dengan BT (Syariz et al. 2015).

\subsection{Pengujian Kualitas Algoritma}

Pengujian kualitas algoritma dilakukan untuk mendapatkan algoritma yang baik dalam merepresentasikan SPL menggunakan R-squared $\left(\mathrm{R}^{2}\right)$ dan Root Mean Square Error (RMSE) (Zareie et al. 2016; Syariz et al. 2015).

$$
R^{2}=\left(\frac{n \sum(y)-\left(\sum x\right)\left(\sum y\right)}{\sqrt{n\left(\sum x^{2}\right)}-\left(\sum x\right)^{2} \sqrt{n\left(\sum y^{2}\right)-\left(\sum y\right)^{2}}}\right)^{2}
$$

Dalam penelitian ini $\mathrm{x}$ dan y berturut-turut merupakan BT dan SPL.

$$
R M S E=\sqrt{\frac{\sum_{i=1}^{n}\left(X_{\text {esti }}-X_{\text {meas }}\right)^{2}}{N}}
$$

Xesti adalah estimasi nilai SPL berdasarkan algoritma dan Xmeas merupaka SPL data insitu.

\section{METEDOLOGI PENELITIAN}

\subsection{Lokasi Penelitian}

Penelitian ini dilaksanakan pada perairan Ponelo, Kabupaten Gorontalo Utara, Provinsi Gorontalo.

\subsection{Data dan Peralatan}

Data yang digunakan adalah data TRIS Landsat-8 level 1T (Path/Row, 113/59) perekaman 21 Mei 2017 dan data insitu suhu permukaan laut tanggal $21 \mathrm{Mei}$ 2017. Pengambilan data insitu menggunakan IR Thermometer Benetech GS320 dan GPSmap76CSx kemudian dianalisa menggunakan software ArcGIS 10.3 dan SAGA GIS.

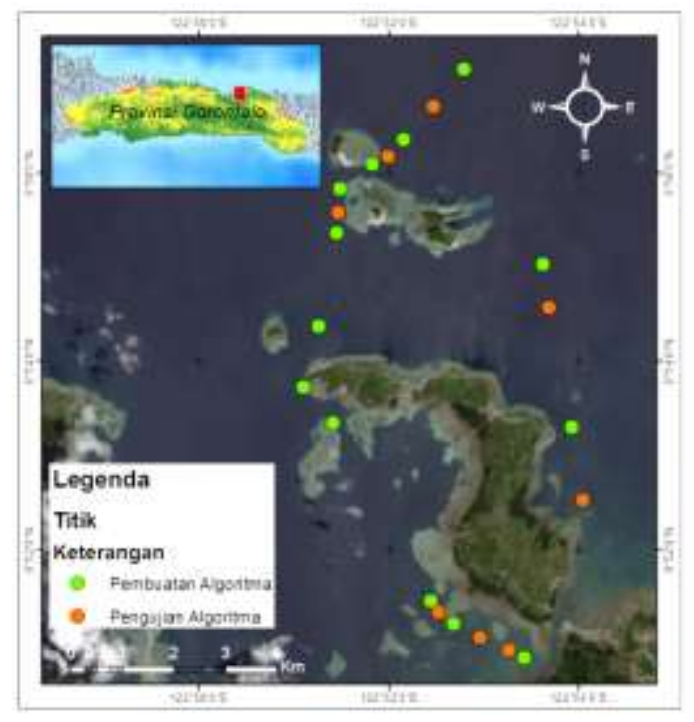

Gambar 1. Lokasi Penelitian dan Sebaran Titik Pengambilan data SPL Insitu

\subsection{Metode Pengolahan Data}

Pengambilan data SPL insitu dilakukan pada saat citra satelit L8 merekam daerah perairan Ponelo. Data yang diperoleh berupa data SPL dan koordinat pengambilan data.

Data TRIS L8 level 1T berupa DN dikalibrasi menjadi data radian menggunakan Persamaan 1. Data Radian dikonversi menjadi BT menggunakan Persamaan 2.

Data SPL dan BT dibandingkan untuk mencari pendekatan korelasi keduanya. Algortitma terbaik merupakan algoritma dengan korelasi terbaik ( $\mathrm{R}$ squared $\left(\mathrm{R}^{2}\right)$ mendekati 1) dan RMSE kecil. 


\section{HASIL DAN PEMBAHASAN}

\subsection{Pembuatan Algoritma}

Model Korelasi antara SPL insitu dan BT data L8 merupakan algoritma SPL pada citra satelit L8. Gambar 2 dan 3 menunjukkan korelasi antara BT dengan SPL.
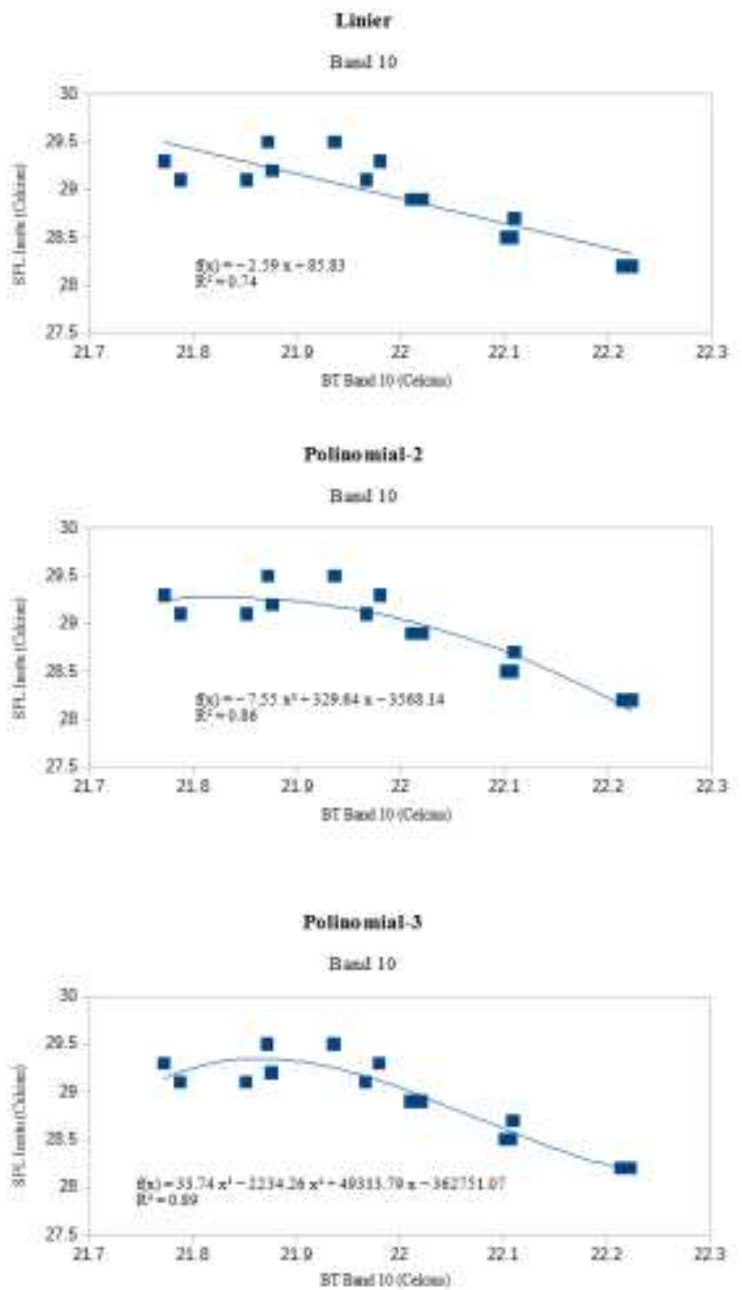

Gambar 2. Korelasi antara BT Band 10 data L8 dengan SPL Insitu

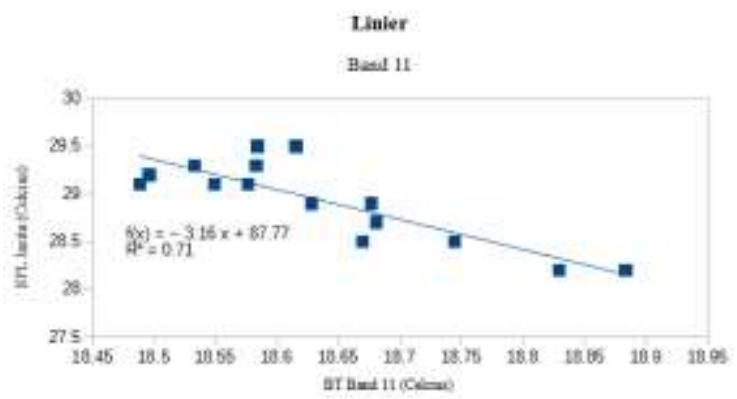

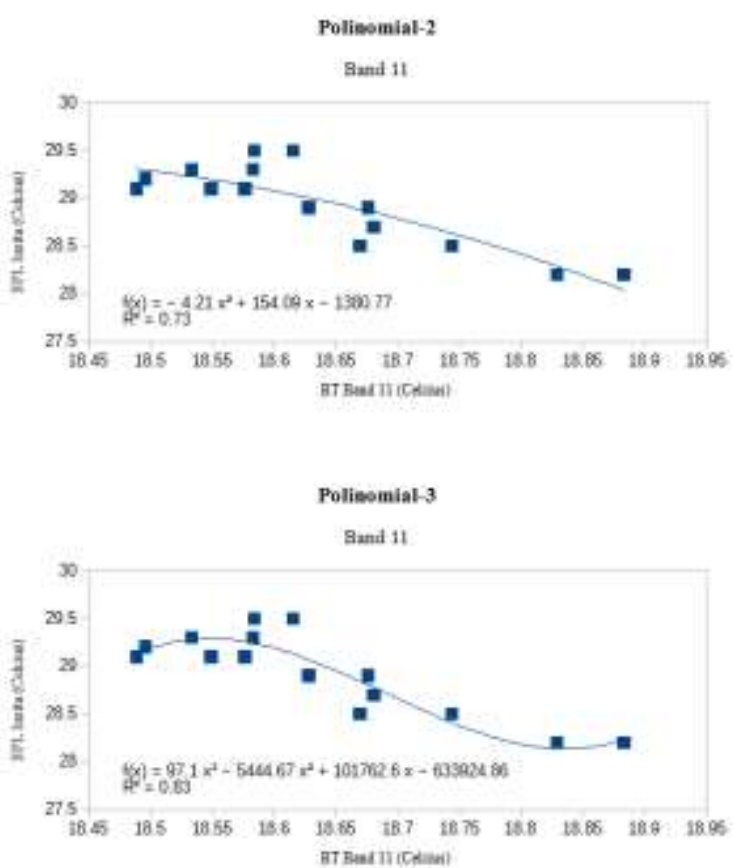

Gambar 3. Korelasi antara BT Band 10 data L8 dengan SPL Insitu

\subsection{Validasi Algoritma}

Perlu dilakukan validasi hasil perbaikan algoritma BT menjadi SPL yang telah diperoleh dari korelasi antara keduanya. Tabel 1 menunjukkan hasil validasi yang dilakukan menggunakan 12 titik menggunakan metode $R$-squared $\left(R^{2}\right)$ dan RMSE.

Tabel 1. Tabel Validasi Algoritma

\begin{tabular}{ccrrr}
\hline \multirow{2}{*}{$\begin{array}{c}\text { Model } \\
\text { Regresi }\end{array}$} & \multicolumn{2}{c}{ Band 10 } & \multicolumn{2}{c}{ Band 11 } \\
\cline { 2 - 5 } & $\mathrm{R}^{2}$ & RMSE & $\mathrm{R}^{2}$ & RMSE \\
\hline Linier & 0.74 & 0.31 & 0.71 & 0.36 \\
Polinomial-2 & 0.86 & 0.73 & 0.73 & 0.50 \\
Polinomial-3 & 0.89 & 4.91 & 0.83 & 16.73 \\
\hline
\end{tabular}

Hasil perbaikan algortima BT menjadi SPL yang baik memiliki nilai $R$-squared $\left(R^{2}\right)$ mendekati 1 dan RMSE kecil. Data pada tabel 1 menunjukkan algoritma pada dengan model pendekatan Polinomial-2 untuk data Band 10 dengan koefisien 
7.55, 329.64, dan 3568.14 merupakan algoritma terbaik dalam penelitian ini.

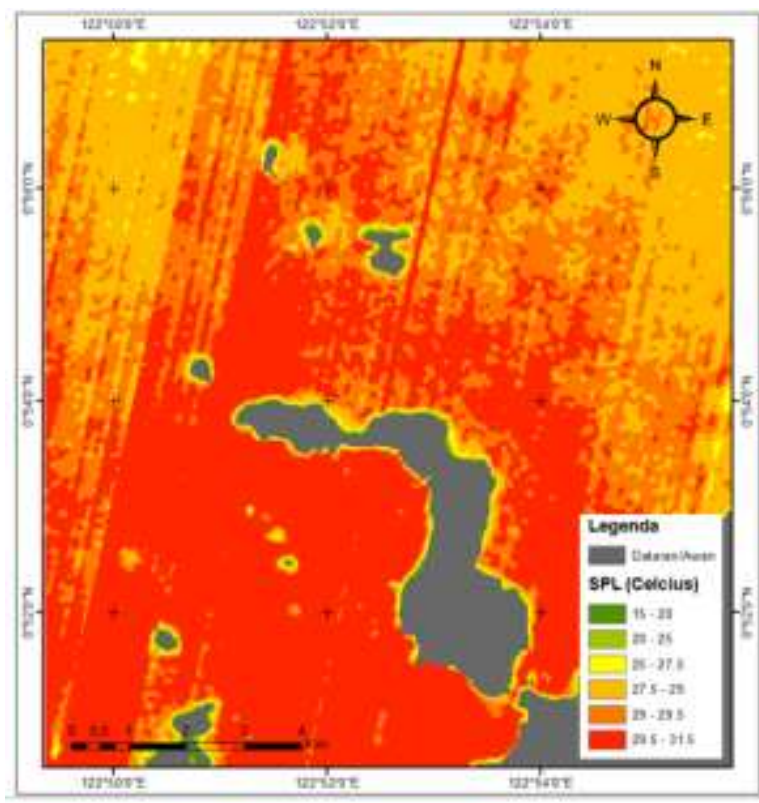

Gambar 4. Peta Suhu Permukaan Laut Perairan Ponelo Tanggal 21 Agustus 2017

\section{PENUTUP}

\section{Kesimpulan}

BT dari hasil pengolahan data TRIS L8 dapat merepresentasikan SPL dengan baik, hal ini ditandai dengan nilai $R$-squared $\left(R^{2}\right)$ lebih besar dari 0.7. algoritma polinomial-2 untuk band 10 dengan koefisien $-7.55,329.64$, dan 3568.14 merupakan algoritma terbaik dalam mengkonfersi BT menjadi SPL pada perairan Ponelo.

\section{Saran}

Berukut ini merupaka saran untuk penelitian berikutnya.

1. Perlu dilakukan pengambilan data untuk perairan sepanjang perairan laut teluk tomini agar diperoleh algortima yang berlaku luas.

2. Perlu dilakukan pengambilan data insitu SPL dengan menggunakan kamera thermal yang terpasang pada UAV sehingga menghemat waktu pengambilan data.

\section{DAFTAR PUSTAKA}

Arief, Muchlisin, Syifa W. Adawiah, Ety Parwati, Rossi Hamzah, and Teguh Prayogo. 2015. "Pengembangan Model Ekstraksi Suhu Permukaan Laut Menggunakan Data Satelit Landsat 8 Studi Kasus: Teluk Lampung ( Development Model of Sea Surface Temperature Extraction Using Landsat- 8 Satellite Data , Case Study :," 107-22.

Jiménez-Muñoz, Juan C., José A. Sobrino, Dražen Skokovi', Cristian Mattar, and J. Cristóbal. 2014. "Land Surface Temperature Retrieval Methods from Landsat-8 Thermal Infrared Sensor Data." Geoscience and Remote Sensing Letters, IEEE 11 (10):1840-43. https://doi.org/10.1109/LGRS.2014.23 12032.

Kartikasari, Fitriana, Lalu Muhamad Jaelani, and Gathot Winarso. 2016. "Analisis Sebaran Konsentrasi Suhu Permukaan Laut Dan pH Untuk Pembuatan Peta Lokasi Budidaya Kerapu Bebek Menggunakan Citra Satelit Landsat -8" 5 (January 2017).

Sahana, Mehebub, Raihan Ahmed, and Haroon Sajjad. 2016. "Analyzing Land Surface Temperature Distribution in Response to Land Use/land Cover Change Using Split Window Algorithm and Spectral Radiance Model in Sundarban Biosphere Reserve, India." Modeling Earth Systems and Environment 2 (2). Springer International Publishing:81. https://doi.org/10.1007/s40808-0160135-5.

Syariz, M. A., L. M. Jaelani, L. Subehi, A. Pamungkas, E. S. Koenhardono, and A. Sulisetyono. 2015. "Retrieval of Sea Surface Temperature over Poteran Island Water of Indonesia with Landsat 8 TIRS Image: A Preliminary Algorithm." International Archives of the Photogrammetry, Remote Sensing and Spatial Information Sciences ISPRS Archives 40 (2W4):87-90. https://doi.org/10.5194/isprsarchivesXL-2-W4-87-2015. 
USGS. 2013a. "Landsat - A Global LandImaging Mission," no. May. . 2013b. "Landsat 8," 3-6.

Zareie, Sajad, Hassan Khosravi, Abouzar Nasiri, and Mostafa Dastorani. 2016. "Using Landsat Thematic Mapper (TM) Sensor to Detect Change in Land Surface Temperature in Relation to Land Use Change in Yazd, Iran.” Solid Earth 7 (6):1551-64. https://doi.org/10.5194/se-7-1551-2016. 